\title{
CONSTRUINDO BRINCADEIRAS E CONHECIMENTOS: RELATOS DE UMA EXPERIÊNCIA NAS SÉRIES INICIAIS DO ENSINO FUNDAMENTAL
}

\author{
Raquel Stoilov Pereira, Centro Universitário de Várzea Grande - Várzea Grande, Mato \\ Grosso - Brasil \\ Evando Carlos Moreira, Universidade Federal de Mato Grosso - UFMT - Cuiabá, Mato \\ Grosso - Brasil
}

\begin{abstract}
RESUMO
O presente estudo tem como objetivo relatar uma experiência de aulas de Educação Física que transcendem o simples "fazer" e "reproduzir", traduzindo-se em apropriação de novos conhecimentos e significados para as crianças, visto a responsabilidade a elas atribuídas para a elaboração das atividades que foram propostas e vivenciadas em aula. Pesquisa-ação de abordagem qualitativa que ocorreu em dois bimestres numa escola pública estadual de Santo André, SP, com a participação de 350 alunos das $3^{\mathrm{a}}$ e $4^{\mathrm{a}}$ séries do Ensino Fundamental. Após o processo de construção e vivência de novas brincadeiras, os alunos compreenderam as aulas de Educação Física como um espaço de construção de conhecimentos, de forma alegre e prazerosa.
\end{abstract}

Palavras-Chave: Educação Física; Séries iniciais do ensino fundamental; Alunos.

\section{MAKING UP JOKES AND KNOWLEDGES: REPORT OF AN EXPERIENCE AT INITIAL GRADES OF HIGH SCHOOL}

\begin{abstract}
The present study has as objective to report an experience in Physical Education classes that transcend the simple act of "doing" and "copying", that can be translated in appropriation of new acquirements and meanings to children, being considered the responsibility that was attributed to them to the preparation of activities that were proposed and experienced in class. It was realized a qualitative action research that occurred for two months at a State Public School in Santo André, São Paulo State, with the participation of 350 students of $3^{\text {rd }}$ and $4^{\text {th }}$ grades of High School. After the process of construction and experience of new games and jokes, the students understood the Physical Education classes as a happy and joyful way of learning.
\end{abstract}

Key-Words: Physical Education; Initial grades of high school; Students.

\section{CONSTRUYENDO JUEGOS Y CONOCIMIENTOS: RELATOS DE UNA EXPERIENCIA EN LOS CURSOS INICIALES DE LA ENSEÑANZA GENERAL BASICA}

Conexões: revista da Faculdade de Educação Física da UNICAMP, Campinas, v. 9, n. 2, p. 198-218, maio/ago. 2011. ISSN: 1983-9030. 


\section{RESUMEN}

El actual estudio tiene como objetivo relatar una experiencia de clase de Educación Física que ultrapasan el simple "hacer" y "reproducir", siendo traducido en la apropiación de nuevos conocimientos y significados para los niños, visto la responsabilidad se ha atribuido a ellos para la elaboración de las actividades que fueran propuestas y experimentadas en clase. Fuera realizado una pesquisa-acción de abordaje cualitativo que se ha ocurrido por dos meses en una escuela pública estatal de la ciudad de Santo André, SP, con la participación de 350 estudiantes del tercero y cuarto cursos de la Enseñanza General Básica. Después del proceso de construcción y experiencia de nuevos juegos, los estudiantes comprendieron las clases de Educación Física como un espacio de la construcción de conocimientos, de una manera alegre y contenta.

Palabras-Clave: Educación Física; Cursos iniciales de la enseñanza general básica; Estudiantes. 


\section{INTRODUÇÃO}

Na escola, o discurso acerca da formação do aluno cidadão, crítico, reflexivo, transformador e, acima de tudo, autônomo torna-se cada vez mais frequente, principalmente, porque essa formação permite a escola e o docente acompanharem e atenderem as mudanças e avanços que a sociedade está submetida. Percebe-se com o desenvolvimento da humanidade a carência, não mais de conhecimentos técnicos e tecnológicos, mas, fundamentalmente, de princípios e valores que auxiliem na constituição de uma sociedade mais igualitária e livre.

Compreendendo a Educação Física como um componente curricular obrigatório da Educação Básica, ${ }^{1-2}$ tendo por finalidade, de acordo com Barbosa, ${ }^{3}$ a formação de cidadãos críticos, autônomos e conscientes, com vistas à transformação da sociedade, cabe a Educação Física:

[...] levar a criança a aprender a ser cidadã de um novo mundo, em que o coletivo não seja sobrepujado pelo individual; em que a ganância não supere a solidariedade; em que a compaixão não seja esmagada pela crueldade; em que a compaixão não seja referencia de vida; em que a corrupção não seja referência de vida; em que a liberdade seja um bem superior; em que a consciência crítica seja o patrimônio de toda pessoa; em que a inteligência não seja reduzida a saber calcular e falar línguas estrangeiras. ${ }^{4}$ (p.32).

Mas será que a Educação Física tem condições de favorecer a formação do aluno em todas essas dimensões? Será que os professores de Educação Física adotam procedimentos de ensino adequados, permitindo aos alunos alcançarem esses objetivos?

Para responder a essas indagações, o objetivo do presente texto é relatar a experiência de aulas de Educação Física que transcendem o simples "fazer" e "reproduzir", traduzindo-se em apropriação de novos conhecimentos e significados para as crianças, visto a responsabilidade a elas atribuídas para a elaboração das atividades propostas e vivenciadas em aula.

Conexões: revista da Faculdade de Educação Física da UNICAMP, Campinas, v. 9, n. 2, p. 198-218, maio/ago. 2011. ISSN: 1983-9030. 


\section{AS AULAS DE EDUCAÇÃO FÍSICA}

Oliveira,${ }^{5}$ Gonçalves e Ferroni ${ }^{6}$ afirmam que, muitas vezes, as aulas de Educação Física se apresentam como sinônimos de práticas de jogos pré-desportivos e esportivos, não havendo preocupação alguma com o "pensar sobre”, com a reflexão do que praticam, com os possíveis questionamentos de quem executa. Nem tampouco se preocupam com os aspectos educacionais e sociais relevantes, restando espaço apenas para o cumprimento de regras préestabelecidas e movimentos estereotipados, demonstrando que a disciplina não tem a definição clara de: objeto de estudo, importância, objetivos, conteúdos, estratégias de ensino, procedimentos avaliativos, enfim, planejamento.

Esses problemas e, a consequente falta de compreensão da disciplina, faz com que ela exista no âmbito escolar apenas pelo cumprimento de questões legais e não por suas finalidades e importância na formação e desenvolvimento do educando, acarretando, segundo Freire ${ }^{7}$ na supervalorização de outras disciplinas, visto que não existem pais que reivindicam aulas de Educação Física na escola, mas, na possível falta de professores ou das aulas de Matemática ou da Língua Portuguesa, as reclamações seriam desmedidas.

Faz-se necessário romper com a ideia de que a atividade desenvolvida nas aulas de Educação Física tem foco no "como fazer", com fim em si mesma, sem significados e explicações para quem a pratica (por quê e para quê fazer?), pois isso acarreta a desvalorização do profissional e da aula de Educação Física na escola.

É também importante substituir a compreensão de que a aula de Educação Física é apenas o momento de brincar e jogar pela compreensão de que ela deve oferecer a oportunidade de conhecer, ensinar, analisar, avaliar, pesquisar e refletir que seus conteúdos propõem. ${ }^{5} \mathrm{O}$ professor precisa perceber que nas aulas de Educação Física seu objetivo deve ser, acima de Conexões: revista da Faculdade de Educação Física da UNICAMP, Campinas, v. 9, n. 2, p. 198-218, maio/ago. 2011. ISSN: 1983-9030. 
tudo, o ser humano e suas manifestações culturais relacionadas ao corpo, ${ }^{8}$ as concepções transmitidas devem transcender a ideia do corpo pelo corpo, ou movimento pelo movimento.

Além disso, o foco de estudo da Educação Física não é qualquer movimento corporal humano ou atividade física, e sim um movimento com intenções e significados pedagógicos permitindo transcender o "fazer pelo fazer", bem como compreender e refletir sobre questões como, por que, para quê e quando fazer., ${ }^{3,9-16}$ Afinal, "A educação física na escola é muito mais do que um bando de crianças correndo atrás de uma bola". ${ }^{17}$ (p. 48).

Assim, o movimento voluntário deve ser o elemento mais presente nas aulas de Educação Física, baseando-se sempre no que é significativo para a criança, permitindo que ela, dia após dia, descubra e se supere a partir de novos movimentos. ${ }^{18}$

Por conseguinte, a função da Educação Física escolar ultrapassa o "simples ensinar" aspectos sobre o corpo ou esporte, sobre a ginástica, a dança, os jogos, as atividades rítmicas e expressivas, pois mais do que aprender a fazer, o aluno deve estar ciente do "porquê" está realizando esse ou aquele movimento, tendo a oportunidade de, ao mesmo tempo, refletir sobre suas atitudes nas práticas corporais. ${ }^{7,19}$

Daolio $^{8}$ entende que a criança precisa ter a oportunidade de refletir sobre seu corpo (quais as suas representações e concepções, de acordo com o contexto cultural), bem como a sua relação com outros corpos. Contudo, o professor deve oportunizar situações permitindo a liberdade de expressões e gestos de acordo com as características individuais de seus alunos, principalmente, porque:

Conexões: revista da Faculdade de Educação Física da UNICAMP, Campinas, v. 9, n. 2, p. 198-218, maio/ago. 2011. ISSN: 1983-9030. 
Quando a criança está correndo, saltando e saltitando pelo espaço, o corpo como um todo expõe-se e revela-se perante tudo e todos. De modo transparente, o corpo revela uma explosão de sentimentos e emoções que podem variar desde alegria, prazer e satisfação, até excitação, frustração, insatisfação entre outros. ${ }^{20}$ (p. 97).

Deve-se considerar ainda, os conhecimentos que a criança traz do ambiente social onde vive, uma vez que ela não espera chegar à escola para começar a aprender. Nem tampouco as aulas de Educação Física são a única oportunidade de jogos e brincadeiras, no entanto, as escolas tendem a tratar os alunos como se fossem vasos ocos que devem ser preenchidos, desconsiderando conhecimentos que poderiam motivar e estimular as aulas..$^{78,20}$

Quando os alunos vêm, é claro, eles trazem com eles, dentro deles, em seu corpo, em suas vidas, eles trazem suas esperanças, desespero, expectativas, conhecimento, que obtiveram vivendo, lutando ou se frustrando. Não há dúvida de que eles não vêm até aqui de mãos vazias. Chegam carregados de coisas. Na maioria dos casos, trazem consigo suas opiniões sobre o mundo, sobre a vida. Trazem consigo seu conhecimento em nível de senso comum e têm o direito de ir além desse nível de conhecimento. [...] Esse é um direito que as pessoas têm, e a que chamo de direito de saber melhor aquilo que elas já sabem (sic.). ${ }^{21}$ (p. 158-159).

O ato de educar não pode ser baseado na "doação do saber" como se o professor fosse um ser sábio que deposita e transmite valores, conhecimentos e informações, por meio de uma relação verticalizada (de cima para baixo) em uma cultura de silêncio, com o professor verbalizando palavras e mais palavras ocas e sem significado, visto que a verdadeira palavra não pertence a um único ser. ${ }^{22}$

Ao apresentar uma nova postura docente, em que o educador fala e ouve, entende-se que o discente também deva ser (re) construído como um ser que ouve e fala, ${ }^{23}$ pois: "Necessitamos de uma educação para a decisão, para a responsabilidade social e política". ${ }^{22}$ (p. 88). Assim, o educando percebe-se como alguém capaz no universo em que está inserido por meio de uma postura de auto-reflexão e reflexão sobre seu tempo e espaço; educando que desconfia, num 
primeiro momento, do que lhe é dito, pois retira-se da situação de coisa, objeto domesticado e alienado para um sujeito que é livre, que tem auto-conhecimento e consciência de sua postura humanizadora (não busca o individual desde que o coletivo seja valorizado), portanto: “[...] O homem, afinal, no mundo e com o mundo. O seu papel de sujeito e não de mero e permanente objeto". ${ }^{24}$ (p. 109).

Por conseguinte, o aluno deve:

[...] Assumir-se como ser social e histórico, como ser pensante, comunicante, transformador, criador, realizador de sonhos, capaz de ter raiva porque é capaz de amar. Assumir-se como sujeito porque capaz de reconhecer-se como objeto. ${ }^{25}$ (p. 46).

No entanto, Freire e Schor $^{23}$ entendem que a escola não favorece uma mudança de posicionamento e abandono da subordinação e alienação, ao passo que muitos professores ainda estão presos ao método que valoriza a transmissão de todos os conteúdos/ informações necessárias para o cumprimento do programa anual, por meio de relações autoritárias que inibem ou pouco valoriza o educando durante as aulas, sendo que aos poucos as pessoas vão se esquecendo que o diálogo não é uma técnica que visa obtenção de resultados ou uma tática como meio, mas algo que representa a própria essência do processo e progresso histórico que as tornam e as fazem seres humanos.

Piaget ${ }^{26}$ relata ainda que como a educação constitui um todo inseparável, é impossível formar um indivíduo autônomo se esse é sempre submetido a aprender o que e como os outros querem, ao passo que não tem a oportunidade de descobrir sozinho a verdade; além disso, “[...] se é passivo intelectualmente, não consegue ser livre moralmente”. (p. 61). 
Ao manter a dependência das crianças os professores apenas perpetuam cidadãos reprodutores, passivos e acríticos, quando deveria ocorrer exatamente o contrário, uma vez que as crianças que podem pensar por si mesmas fazem muito mais progressos. A aquisição da autonomia, criticidade e busca da transformação pode ser facilitada a partir das brincadeiras. Brincando as crianças são levadas a resolverem os problemas, seja pelo não cumprimento das regras ou mesmo pelas suas mudanças. Por meio dos conflitos as crianças vivenciam e solucionam situações inesperadas, enriquecem as relações com seus pares e atuam de forma ativa e construtiva, como ser que é.

Nesse sentido, o professor atuaria como um espectador ativo que, ao mesmo tempo em que assiste, permite que as crianças resolvam seus conflitos, interferindo quando os pequenos não alcançam um ponto comum. Interferir não é dar respostas prontas e acabadas, mas pistas, possíveis caminhos que facilitariam o entendimento comum, portanto adotando uma postura de mediador e não de ditador.

As brincadeiras também permitem as crianças estarem em contato físico e social com seus pares, fortalecendo os relacionamentos e, ampliando o sentido de pertencer a um grupo; estimulam a imaginação e a formação da identidade; permitem que as crianças desenvolvam a confiança em suas habilidades; favorecem a aquisição de liderança, cooperação, papéis e regras. Por conseguinte, as brincadeiras são os momentos mais apropriados das crianças demonstrarem suas habilidades, tendo outras tantas crianças para observá-las, pois não adianta ter determinada habilidade se não tenho ninguém e nenhuma oportunidade para demonstrála. ${ }^{27}$ 
Portanto, a brincadeira precisa estar presente no espaço escolar, pois: “[...] é a garantia de uma possibilidade de educação da criança em uma perspectiva criadora, voluntária e consciente", ${ }^{28}$ (p. 31), que pode, perfeitamente, ser mediada pelo professor de qualquer área do conhecimento e não, especificamente, pelo professor de Educação Física.

Mas, para que tudo isso ocorra, o professor não deve aplicar as famosas receitas de atividades, mas sim problematizá-las, aproximá-las ao máximo da vida das crianças, por meio de atividades criativas que considerem suas experiências de vida, bem como a do professor, ampliando cada vez mais as relações e possibilidades de professor-conhecimento-aluno.

As aulas de Educação Física nas séries iniciais do Ensino Fundamental ( $1^{\mathrm{a}}$ a $4^{\mathrm{a}}$ séries), geralmente, são propostas em forma de brincadeiras, visando ampliar o interesse por parte dos alunos em realizá-las. No entanto, muitas vezes, essas brincadeiras apresentam-se descontextualizadas, pois os alunos vão para a quadra, escutam a explicação de determinada atividade, executam-na e voltam para a sala de aula, sem um espaço para reflexão, criação e maior envolvimento com as propostas.

Assim, na perspectiva de que as aulas de Educação Física carecem de novos olhares, surge a ideia de relatar uma experiência que transcende o simples "fazer" e "reproduzir", traduzindo em conhecimentos significados para as crianças, uma vez que os próprios alunos são os responsáveis pela elaboração das atividades que serão propostas em aula.

\section{PROCEDIMENTOS METODOLÓGICOS}

O estudo caracteriza-se como uma pesquisa-ação, visto que existe uma ampla e explícita interação entre pesquisador e os sujeitos da pesquisa e durante o processo há um

Conexões: revista da Faculdade de Educação Física da UNICAMP, Campinas, v. 9, n. 2, p. 198-218, maio/ago. 2011. ISSN: 1983-9030. 
acompanhamento das decisões e das ações tomadas, tendo como objetivo resolver ou esclarecer os problemas da situação vivida, ou seja, daquilo que ocorre. ${ }^{29}$ Também adotou como método a abordagem qualitativa, pois não teve a intenção de numerar ou medir durante a análise do problema. ${ }^{30}$ (p. 117).

O universo desta pesquisa corresponde a uma escola da rede estadual de São Paulo, localizada em Santo André, Região do Grande $\mathrm{ABC}$ da cidade de São Paulo, contando com a participação de 10 salas de $3^{\mathrm{a}}$ e $4^{\mathrm{a}}$ séries do Ensino Fundamental, totalizando 350 alunos.

Os alunos de cada uma das 10 salas foram divididos em 7 grupos por turma, totalizando 70 grupos, sendo a atividade desenvolvida durante o terceiro e quarto bimestres do ano letivo, com a utilização de 20 aulas.

\section{RELATO DA EXPERIÊNCIA}

A proposta inicial foi que cada grupo criasse/ inventasse uma brincadeira nova, a partir das experiências cotidianas e das atividades vivenciadas nas aulas de Educação Física e depois a relatassem para a professora.

Nessa fase, percebeu-se a dificuldade das crianças em criar algo novo. Em muitos casos, as crianças realizavam pequenas alterações em brincadeiras já existentes (mudança do nome, material, tempo de duração ou espaço) entendendo que isso era uma criação/ invenção. No entanto, quando relatavam a ideia a professora incentiva os alunos a, de fato, criarem algo próprio, ou seja, utilizar a capacidade inventiva, num movimento constante de trocas e mudanças de rumo, em função da necessidade do grupo, algo característico da pesquisa-ação. 
Quando os grupos criavam/inventavam uma atividade e essa era "aprovada" pela professora, iniciava-se a segunda parte do trabalho, momento em que os alunos organizavam suas ideias no papel. Esse movimento de criação/ invenção, apresentação a professora e ajustes a partir das sugestões ocorreu durante 02 aulas.

Após as idas e vindas, bem como do exercício constante de criação/ invenção, cada grupo recebeu um roteiro composto pelos seguintes itens: nomes dos alunos participantes; nome da atividade; objetivos da atividade; regras da atividade, tais como atividade individual ou em grupo, espaço utilizado e/ ou delimitado, a duração e os materiais necessários; e, por último, a descrição detalhada do "como jogar". Vale ressaltar que os itens que compõem as regras da atividade tinham exemplos para que as crianças encontrassem a melhor alternativa para a atividade elaborada pelo grupo. O roteiro apresentado às crianças foi o seguinte:

Quadro 1- Roteiro para elaboração das atividades

Série:
1. Criadores:
2. Nome da atividade:
3. Objetivos da atividade:
4. Regras da atividade:
Atividade individual ou em grupo:
- A atividade é individual, cada um por si;
- A atividade é em grupo, com_ grupos;
- A atividade é realizada em alguns momentos em grupo e em outros
individualmente.
Término da atividade:
- A atividade termina depois de__ minutos.
- A atividade termina quando uma das equipes marcar__ pontos.
- A atividade termina quando todos os alunos_
Espaço:
- A atividade ocorre na quadra inteira.
- A atividade ocorre em meia quadra.
Material necessário e quantidade:
Explicação detalhada de como jogar:

Conexões: revista da Faculdade de Educação Física da UNICAMP, Campinas, v. 9, n. 2, p. 198-218, maio/ago. 2011. ISSN: 1983-9030. 
Quando os grupos concluíram essa segunda etapa, iniciaram-se os "testes das atividades". Nesses testes cada grupo apresentou a sua atividade para os colegas da turma, e todos a vivenciaram, configurando-se num momento de avaliação, visto que as crianças perceberam se o que idealizaram deu certo ou não, bem como auxiliaram no aperfeiçoamento, pois toda turma teve a oportunidade de opinar sobre os pontos positivos e negativos das 7 atividades criadas na turma, sendo um momento significativamente rico, principalmente no que diz respeito ao diálogo e aceitação de críticas elogios.

Após as apresentações e alterações que os grupos julgaram necessárias nos testes e interferência dos colegas, iniciou-se a terceira etapa. Nesse momento, as crianças confeccionaram cartazes, os quais foram expostos nos corredores da escola para que todos pudessem conhecer as atividades das outras salas, bem como a formação de manuais das brincadeiras/caderno de atividades, para registro da escrita (com todas as informações contidas no roteiro) e ilustração de cada uma das atividades criadas/ inventadas e já testadas e avaliadas pelos colegas da sala ${ }^{\mathbf{1}}$. A ilustração foi realizada pelos próprios alunos, facilitando a visualização e compreensão das atividades.

Identificaram-se desenhos belíssimos! Não seria possível inserir todas as produções, mas optou-se por apresentar pelo menos uma delas, apenas para visualização do que está sendo relatado.

\footnotetext{
${ }^{1}$ A justificativa para os alunos foi de que a ilustração auxiliaria aos demais alunos compreenderem melhor as explicações da brincadeira criada/ inventada. No entanto, além dessa intenção, também pensou-se em oportunizar aos alunos o desenvolvimento de diferentes habilidades, quer seja de criação, escrita ou desenho, garantindo o alcance de diferentes potencialidades das crianças.

Conexões: revista da Faculdade de Educação Física da UNICAMP, Campinas, v. 9, n. 2, p. 198-218, maio/ago. 2011. ISSN: 1983-9030.
} 
1. Criadores: T, X, W, Y, Z

Série: $4^{\mathrm{a}} \mathrm{G}$

Grupo 5

2. Nome da atividade: Bambom-cego

3. Objetivos da atividade: Arremessar, a partir das orientações auditivas de um colega.

4. Regras da atividade:

* A atividade é em grupo, com 3 pessoas em cada grupo (trios).

- A atividade termina quando todos os alunos participarem.

* A atividade ocorre na quadra inteira.

* Material e quantidade: 11 bolas de borracha, 11 vendas, 11 arcos.

* Como jogar: Os alunos estarão divididos em trios. Uma pessoa segurará um arco sem se movimentar, a outra ficará com os olhos vendados e o terceiro será o guia, que ajudará durante o arremesso. A pessoa vendada, com a ajuda do guia, arremessará a bola de borracha dentro do arco. Depois do arremesso, trocaremos de posições até que todos experimentem segurar o arco, arremessar e ser guia.

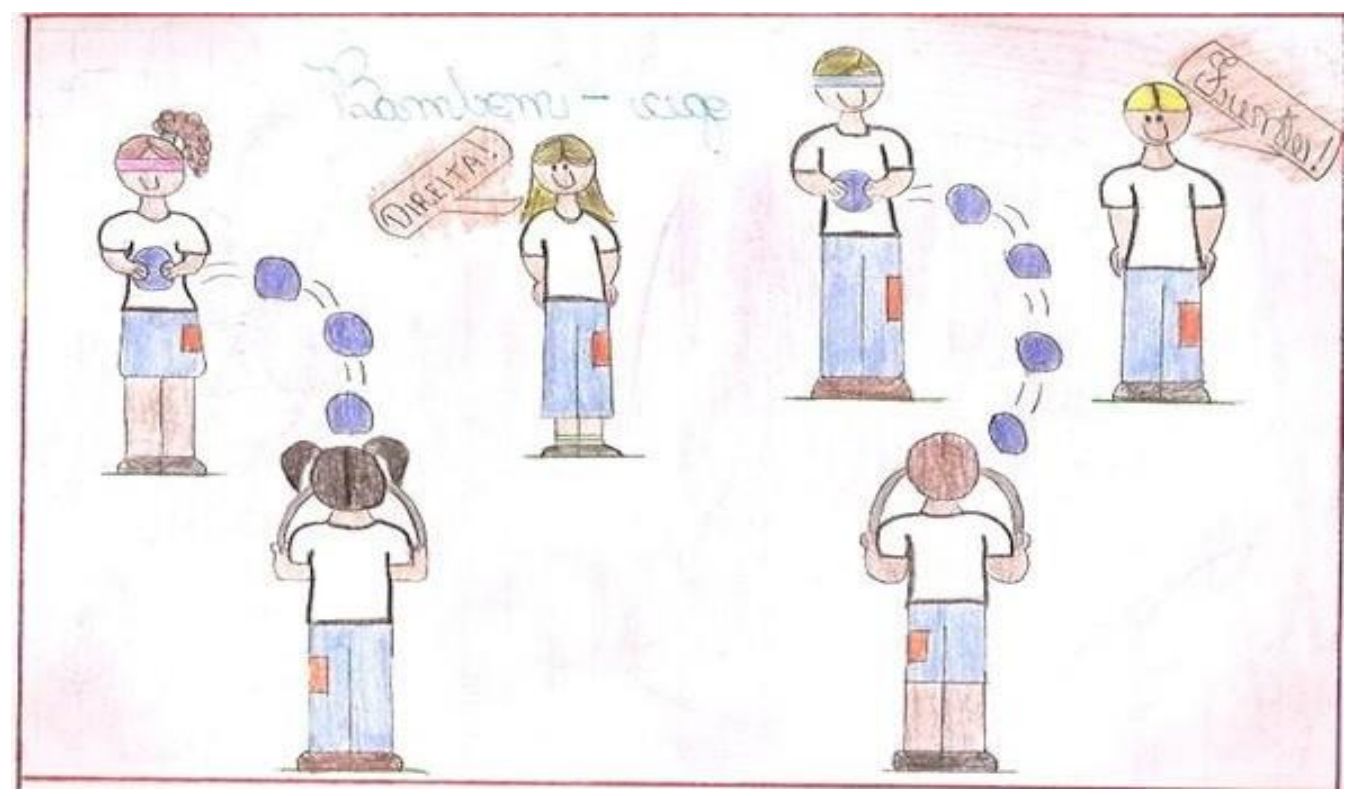

Figura 1: Apresentação de brincadeira elaborada pelos alunos.

A estratégia adotada permitiria aos alunos conhecerem as atividades de todas as salas participantes, para a realização de um festival de brincadeiras entre turmas dos mesmos anos, ou seja, terceiras séries com terceiras séries e quartas séries com quartas séries, com a atividade mais votada por eles.

No entanto, pensou-se, a posteriori, na possibilidade das crianças escolherem mais de uma atividade que seria realizada na própria sala. Assim, ao invés de vivenciarem uma única 
atividade com outras salas, as crianças teriam a oportunidade de conhecer 4 novas atividades, vivenciando-as com os próprios colegas de sala nas aulas de Educação Física.

Após propor essas duas possibilidades para os alunos, partiu-se para uma votação. Os alunos escolheram a segunda opção, alegando que seria mais interessante conhecer outras brincadeiras, ao invés de realizar uma única com outra sala, o que deixaria a quadra com muitos alunos, diminuindo o tempo de vivência da atividade eleita.

Assim, na quarta etapa da proposta, as crianças escolheram 4 atividades criadas/ inventadas pelos colegas de outras salas e experenciaram cada uma delas. Para a efetivação dessa intenção, a professora foi a responsável por esclarecer possíveis dúvidas das atividades escolhidas, caso a explicação presente no roteiro de atividade e ilustração não estivesse de todo clara.

Após vivenciaram as atividades dos colegas de outras salas era muito comum ouvir os alunos dizerem: "Nossa que atividade legal, porque não pensei nisso!"; "Essa atividade ficaria mais legal se tivesse mais de uma bola". Por conseguinte, percebeu-se que os alunos ficaram mais críticos e propositivos, inclusive nos momentos de intervalo de aulas os alunos chegavam até a procurar os "inventores" das outras salas para sugerirem alterações nas brincadeiras por eles inventadas.

Na quinta etapa a professora propôs as crianças que desenhassem a atividade que mais tinham gostado, além de uma explicação do porquê dessa escolha. Esse momento foi muito significativo, pois os alunos tiveram a oportunidade de se expressar individualmente, desde a 
escolha da atividade, a ilustração e a escrita. A seguir, a produção de uma das crianças da $4^{\text {a }}$ série.

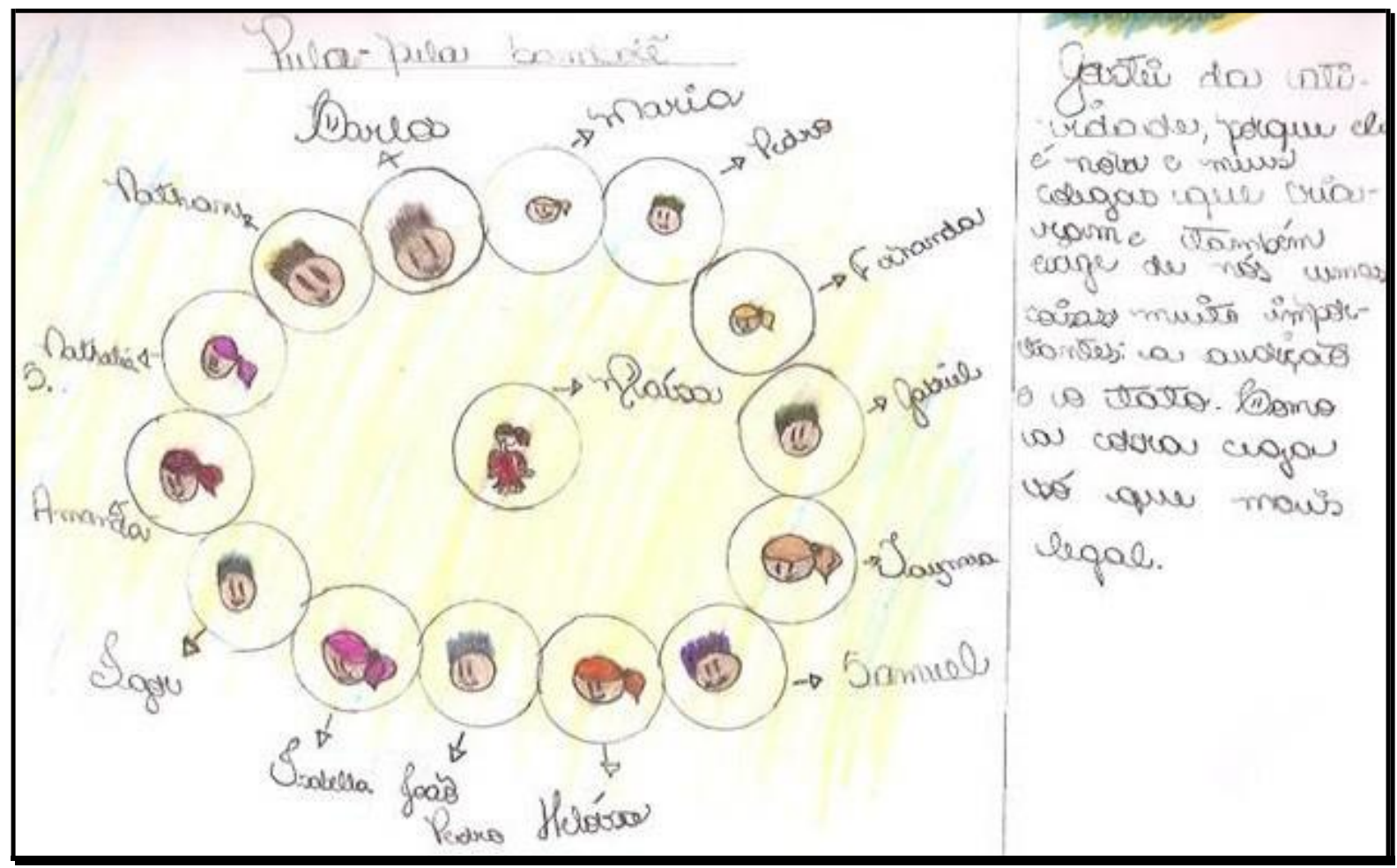

Figura 2: Apresentação da atividade que um dos alunos mais gostou de participar.

Para o encerramento da proposta, a professora sugeriu a realização de uma exposição aos demais alunos da escola e familiares, incluindo desde os cartazes, caderno de brincadeiras, além das ilustrações e justificativas elaboradas individualmente. Os alunos aceitaram imediatamente e com essa ação encerrou-se a proposta de criação de brincadeiras.

Ao total utilizaram-se 20 aulas, sendo:

- 02 para elaboração da atividade;

- 02 para elaboração da explicação da atividade, a partir do roteiro disponibilizado pela professora;

- 07 para vivência e alterações, quando necessário, das atividades elaboradas;

Conexões: revista da Faculdade de Educação Física da UNICAMP, Campinas, v. 9, n. 2, p. 198-218, maio/ago. 2011. ISSN: 1983-9030. 
- 03 para confecção dos cartazes, alterações na explicação das atividades e elaboração da ilustração da brincadeira;

- 04 para vivenciar as brincadeiras elaboradas pelas outras salas;

- 01 para produção individual com ilustração e texto;

- 01 para exposição para os familiares e demais alunos.

Todo esse processo não foi simples, principalmente, com as terceiras séries que demonstraram muita imaturidade em todas as etapas, além da dificuldade de escrita. Para àqueles que gostaram da ideia e pretendem aplicá-la, ressalta-se que quanto mais alterações o docente fizer para aproximar sua proposta da realidade de seus alunos melhor será, não precisando prenderse a nenhuma regra. Ou seja, não é porque na experiência relatada utilizou 20 aulas que o professor deverá seguir esse padrão. Pelo contrário, é fundamental adaptar-se a realidade das crianças, bem como a própria maturidade das turmas, pois se diferenças foram encontradas entre salas da mesma série, imaginem em escolas diferentes!

\section{CONSIDERAÇÕES FINAIS}

A partir do momento em que os alunos compreenderam o processo de elaboração de uma atividade e aplicaram-na a outras pessoas, aumentou o interesse pelas aulas de Educação Física, além da compreensão do quão complexo é esse processo.

De certa forma, os alunos perceberam que a Educação Física é uma disciplina composta não apenas de brincadeiras, mas um momento em que podem aprender, a partir da construção do conhecimento de forma lúdica e prazerosa. 
A comprovação do interesse dos alunos nesta atividade, proposta em um bimestre, se deu quando as crianças da $3^{\text {a }}$ série, que continuariam na escola no próximo ano, pediram que o trabalho fosse repetido.

Nas atividades propostas após esta experiência, os alunos mostraram-se muito mais críticos acerca dos objetivos das atividades, materiais envolvidos e, principalmente, as regras estabelecidas, uma vez que pararam de aceitar passivamente as informações, visto que sempre tinham algo a acrescentar.

Isso caracteriza um processo de apropriação de conhecimentos, aquisição de criticidade e autonomia, pensar por si mesmo e em função das necessidades do grupo, o que em curto prazo permitirá a criança tomar decisões de maneira espontânea e segura.

Assim, o objetivo de construir o conhecimento com as crianças para o além do "simples" brincar foi presente durante o desenvolvimento das atividades, contribuindo para a implantação de uma Educação Física além da quadra, do jogar e da bola, que substitui o reproduzir pelo produzir com condições efetivas de contribuição na formação do aluno crítico, consciente e autônomo.

\section{REFERÊNCIAS}

${ }^{1}$ BARBOSA, C. L. de. Educação física escolar: da alienação à libertação. 3. ed. Petrópolis: Vozes, 2001.

${ }^{2}$ BRASIL. Presidência da Republica. Congresso Nacional. Lei ${ }^{\circ}$ 9.394, de 20 de dezembro de 1996. Estabelece as Diretrizes e Bases da Educação Nacional. Diário Oficial [da]

Conexões: revista da Faculdade de Educação Física da UNICAMP, Campinas, v. 9, n. 2, p. 198-218, maio/ago. 2011. ISSN: 1983-9030. 
República Federativa do Brasil, Poder Executivo, Brasília, DF, 23 dez. 1996. Seção I, p. 27833-27841.

${ }^{3}$ BRASIL. Presidência da Republica. Congresso Nacional. Lei n. 10.328, de 12 de dezembro de 2001. Introduz a palavra obrigatório após a expressão curricular, constante do parágrafo $3^{\circ}$ artigo 26 da Lei 9.394, de 20 de dezembro de 1996, que estabelece as diretrizes e bases da educação nacional. Diário Oficial [da] República Federativa do Brasil, Poder Executivo, Brasília, DF, 23 dez. 2001. Seção I, p. 1.

${ }^{4}$ FREIRE, J. B.; SCAGLIA, A. J. Educação como prática corporal. São Paulo: Scipione, 2003.

${ }^{5}$ OLIVEIRA, A. A. B. de. Analisando a prática pedagógica da Educação Física. Revista da Associação dos Professores de Educação Física de Londrina, Londrina, v. 7, n. 13, p. 1114, jul. 1992.

${ }^{6}$ GONÇALVES, C. T.; FERRONI, G. S. A desconsideração ao professor de Educação Física na escola. 2003. 52 f. Trabalho de Conclusão de Curso (Graduação) - Curso de Educação Física, Faculdades Integradas de Santo André, Santo André, 2003.

${ }^{7}$ FREIRE, J. B. Educação de corpo inteiro: teoria e prática da educação física. 4. ed. São Paulo: Scipione, 1997.

${ }^{8}$ DAOLIO, J. Educação física e o conceito de cultura. Campinas: Autores Associados, 2004.

Conexões: revista da Faculdade de Educação Física da UNICAMP, Campinas, v. 9, n. 2, p. 198-218, maio/ago. 2011. ISSN: 1983-9030. 
${ }^{9}$ PEREZ GAllardo, J. S.; OliVEIRA, A. A. B.; ARAVENA, C. J. O. Didática de Educação Física: a criança em movimento: jogo, prazer e transformação. São Paulo: FTD, 1998.

${ }^{10}$ FERRAZ, O. L.; MACEDO, L. de. Educação física na educação infantil do município de São Paulo: diagnóstico e representação curricular em professores. Revista Paulista de Educação Física, São Paulo, v. 15, n. 1, p. 63-82, jan./jun. 2001.

${ }^{11}$ NISTA-PICCOLO, V. L.; VELARDI, M.; TOLEDO, E. Os desafios da educação física escolar: seus conteúdos e métodos. In: MOREIRA, E. C.; NISTA-PICCOLO, V. L. (Org.). O quê e como ensinar educação física na escola. Jundiaí: Fontoura, 2009a. p. 21-26.

12 NISTA-PICCOLO, V. L.; VELARDI, M.; TOLEDO, E. O quê ensinar nas aulas de educação física. In: MOREIRA, E. C.; NISTA-PICCOLO, V. L. (Org.). O quê e como ensinar educação física na escola. Jundiaí: Fontoura, 2009b. p. 27-62.

${ }^{13}$ NISTA-PICCOLO, V. L.; VELARDI, M.; TOLEDO, E. Como ensinar esses conteúdos nas de educação física. In: MOREIRA, E. C.; NISTA-PICCOLO, V. L. (Org.). O quê e como ensinar educação física na escola. Jundiaí: Fontoura, 2009c. p. 63-89.

${ }^{14}$ MOREIRA, E. C.; PEREIRA, R. S.; LOPES, T. C. Considerações, reflexões e proposições para a educação física na educação infantil e séries iniciais do ensino fundamental. In: MOREIRA, E. C.; NISTA-PICCOLO, V. L. (Org.). O quê e como ensinar educação física na escola. Jundiaí: Fontoura, 2009a. p. 109-149. 
${ }^{15}$ MOREIRA, E. C.; PEREIRA, R. S.; LOPES, T. C. Consolidando caminhos e caminhadas da educação física nas séries finais do ensino fundamental. In: MOREIRA, E. C.; NISTAPICCOLO, V. L. (Org.). O quê e como ensinar Educação Física na escola. Jundiaí: Fontoura, 2009b. p. 151-175.

${ }^{16}$ MOREIRA, E. C.; PEREIRA, R. S.; LOPES, T. C. Desafios e propostas para a educação física no ensino médio. In: MOREIRA, E. C.; NISTA-PICCOLO, V. L. (Org.). O quê e como ensinar educação física na escola. Jundiaí: Fontoura, 2009c. p. 177-197.

${ }^{17}$ CRUZ, A. C. Educar e competir. Revista Crescer, São Paulo, n. 160, p. 48-49, mar. 2007.

${ }^{18}$ MATTOS, M. G. de.; NEIRA, M. G. Educação física infantil: construindo o movimento na escola. 3. ed. Guarulhos: Phorte, 2000.

19 DARIDO, S. C. Os conteúdos da educação física escolar: influências, tendências, dificuldades e possibilidades. Perspectivas em Educação Física Escolar, Niterói, v. 2, n. 1 (supl.), 2001.

${ }^{20}$ PORTO, E. T. R. Mensagens corporais na pré-escola: um discurso não compreendido. In: MOREIRA, W. W. (Org.). Corpo pressente. Campinas: Papirus, 1995. cap. 4. p. 83-110.

${ }^{21}$ BEEL, B. et al. O caminho se faz caminhando: conversas sobre educação e mudança social. Petrópolis: Vozes, 2003.

${ }^{22}$ FREIRE, P. Pedagogia do oprimido. 17. ed. Rio de Janeiro: Paz e Terra, 1987.

Conexões: revista da Faculdade de Educação Física da UNICAMP, Campinas, v. 9, n. 2, p. 198-218, maio/ago. 2011. ISSN: 1983-9030. 
${ }^{23}$ FREIRE, P.; SCHOR, I. Medo e ousadia: o cotidiano do professor. Rio de Janeiro: Paz e Terra, 2000.

${ }^{24}$ FREIRE, P. Educação como prática da liberdade. Rio de Janeiro, Paz e Terra, 1989.

${ }^{25}$ FREIRE, P. Pedagogia do oprimido: saberes necessários à prática educativa. São Paulo, Paz e Terra, 2001.

${ }^{26}$ PIAGET, J. Para onde vai a educação? 7. ed. Rio de Janeiro: José Olympio, 1980.

${ }^{27}$ PAPALIA, D. E.; OLDS, S. W. Desenvolvimento humano. 7. ed. Porto Alegre: Artmed, 2004.

${ }^{28}$ WAJSKOP, G. Brincar na pré-escola. 6. ed. São Paulo: Cortez, 2005.

${ }^{29}$ THIOLLENT, M. Metodologia da pesquisa-ação. São Paulo: Cortez, 2003.

${ }^{30}$ OLIVEIRA, S. L. de. Tratado de metodologia científica: projetos de pesquisa, TGI, TCC, monografias, dissertações e teses. São Paulo: Pioneira, 2000. 